\title{
Here or There? How Configuration of Transnational Teams Impacts Social Capital
}

\author{
Julia Katherine Haines, Judith S. Olson, and Gary M. Olson \\ Donald Bren School of Information and Computer Sciences \\ University of California, Irvine, USA \\ \{hainesj, jsolson, gary.olson\} @uci.edu
}

\begin{abstract}
The many challenges of distributed communication and the many challenges of intercultural collaboration have been researched and discussed at length in the literature. What is lacking is a combined approach that looks at both issues of distance and diversity in collaboration. We conducted research in a large, multinational technology company to better understand team configurational factors in transnational work. In this case study, we found that the development of social capital is impacted by whether a person is in their home context or transplanted and their expectations based on that context. This has implications for the development of intellectual capital in the team. We highlight factors in the creation of social capital as well as some mechanisms that may mitigate cultural difference. In addition to bringing into focus the challenges that arise in various configurations, this study contributes to the transnational literature by highlighting the importance of local context in diverse collaborations.
\end{abstract}

Keywords: Transnational collaboration, team configuration, social capital.

\section{Introduction}

Many organizational structures today are truly global. Companies find talent all over the world, place employees in all sorts of geographic locations, and coordinate teams, both distributed and co-located [1]. This sort of transnational work requires crossing all sorts of important boundaries, including temporal, spatial, and cultural. Much has been written about the multitude of issues in working across spatial and temporal distances [2-6]. And a great deal of research has focused on transnational or crosscultural differences as they related to the workplace [7-9]. Yet, given the prevalence and significance of transnational work in today's globalized world, there appears to be a lack of empirical studies that focus on the variety of ways such collaboration can be structured and the consequences of different configurations [10-13]. Global organizations can choose to configure and structure their teams in a wide variety of ways, and it is important to look at the costs and benefits associated with these choices.

First, why might you want to have diverse cultural configurations? Research that has focused on the value of diversity in groups illustrates that, for many tasks, diversity trumps homogeneity [14] by allowing for a diversity of perspectives, which aid in a 
number of ways, such as problem solving, information aggregation, and prediction. Other studies have indicated that cultural diversity leads to increased creativity and satisfaction of experience [15], and with the right mechanisms in place, can result in better cohesion, trust, and innovation [16]. Most work in this area suggests, however, that the net benefits of such diversity must account for the costs related to differences in cognitive, behavioral, and affective aspects [13]. Diversity can most certainly be an asset, but it can also a liability if not structured and managed well.

Second, from an organization's perspective, why might you choose to have a team distributed over continents and time zones as opposed to co-located in one area? As Castells and others have suggested, today's knowledge-based workforces are defined by their flexibility and adaptability [17], and it is quite possible to configure teams in many ways [18]. Benefits to globally distributed collaboration include garnering expertise in local markets, cost reductions, and a 24-hour development cycle [19, 20]. But, there are still many challenges for distributed teams in terms of processes, tools, and structuring $[1,21]$. And, there are particular difficulties for distributed teams that cross cultures $[13,22]$.

With all the permutations possible, it is important to understand the implications of various transnational team configurations. In our research, we found that the most salient implications are related to interpersonal relationships. Thus, we use the theory of social capital in framing our findings. This theory highlights the importance of interpersonal relationships, which serve as a valuable resource for social action within a network [23]. Nahapiet and Ghoshal's work on social capital in the organization shows that social relationships within a firm, which are the foundations of social capital, are intricately tied to the firm's ability to create new intellectual capital, or knowledge [23]. This theory serves well as a lens to investigate the transnational configurations within firms, enabling insight into interpersonal relationships at the individual level as well as insight into overall team and organizational functioning.

In this paper, we contribute to the transnational literature by examining how the configuration of global teams and the context of an individual's location within that team impact social capital. We seek to examine how distributed and co-located configurations of transnational teams are similar and different in terms of the social relationships that are developed, and in turn, how that impacts the individual and the team. We recognize, as others do $[11,24]$, that one's culture is not static, and that although culture influences one's behavior, behavior is also influenced by the situation. Over time people adapt to their context, either converging toward the local culture or diverging. Thus, we focus on these central ideas of location and configuration.

\section{$2 \quad$ Method}

We conducted research within a large, multinational high-technology company, which we will refer to by the pseudonym PrimaTech. PrimaTech is headquartered in the US, but has offices in more than 40 countries worldwide. The structure of the organization is complex and dynamic, with many teams distributed all over the globe. 


\subsection{Participants}

We specifically chose to focus on participants from India and China, as a significant portion of PrimaTech's employees come from these two countries. Participants were independently recruited at multiple work sites using a purposive sampling methodology [25]: we broadcast our study requirements on various listservs, and when people responded, we selected them according to their background, work situation, and availability for interview. Among the 22 we selected, nine of whom were female, all were of Indian (13) or Chinese (9) national origin currently working in either the US or offices in their home country, and all participants had previously or were currently collaborating in a transnational team. Thirteen were based currently in the US, nine in offices abroad (Bangalore, Beijing, and Hyderabad). Six had spent two or more years in the US offices, eight less than two years, and eight spent no time at US offices. Table 1 shows these participant aspects in more detail.

\subsection{Interviews}

Prior to data collection, we conducted extensive background research to better understand common cultural characteristics amongst the various national cultures we considered for the study. In all, we created a bibliography of 88 sources. From this meta-analysis, we created an informational table that included aspects of culture in the US, China, India, Japan, Korea, and Singapore along 29 dimensions, including behavioral elements, cognitive and perception differences, and macro-level social conventions. This table was used to inform the interview script. We conducted pilot interviews with contacts of Chinese and Indian origin and refined the scripts according to their feedback, which included areas for further inquiry as well as suggestions on how to approach certain delicate topics.

The interviews themselves were conducted in a semi-structured format to encourage participants to openly discuss their perspectives and reflect on experiences. We collected information on participants' backgrounds and their work at PrimaTech, including team collaboration methods and tools, their cross-cultural experiences, and perspectives on differences in communication and social conventions. We visited the company's US headquarters and conducted a portion of the recruiting there, but all interviews were conducted remotely via video-conferencing. Interviews lasted from around 45 minutes to over an hour. Participants were not compensated.

\section{$2.3 \quad$ Teams}

Teams at PrimaTech are often comprised of people of many nationalities, so participants were not necessarily working primarily with American-born colleagues, but truly transnational teams. We use the term transnational here to indicate that the teams were composed of two or more nationalities, indicating diversity that goes beyond just different cultures, which can occur within nations [13]. In this research, we look both at transnational teams with participants in their home countries of India and China 
Table 1. Characteristics of Participants

\begin{tabular}{|c|c|c|c|c|c|c|c|c|c|c|}
\hline T/R* & Gender & Nation & Loc. & $\begin{array}{l}\text { Yrs at } \\
\text { Co. }\end{array}$ & $\begin{array}{l}\text { Yrs US } \\
\text { Office }\end{array}$ & Role & $\begin{array}{l}\text { \# Offices } \\
\text { work } \\
\text { with }\end{array}$ & $\begin{array}{l}\text { Time } \\
\text { on } \\
\text { team } \\
\text { (yrs) }\end{array}$ & $\begin{array}{l}\text { Team } \\
\text { size*** }^{*}\end{array}$ & $\begin{array}{l}\text { Some } \\
\text { Members } \\
\text { Co-located }\end{array}$ \\
\hline $\mathrm{T} 1$ & $M$ & India & US & 3 & 0.5 & Manager & 4 & $<1$ & $\mathrm{~L}$ & $\mathrm{Y}$ \\
\hline $\mathrm{T} 2$ & F & China & US & 8 & 8 & Infrastructure & 7 & $>1$ & $\mathrm{~L}$ & $\mathrm{Y}$ \\
\hline T3 & M & China & US & 6 & 6 & Engineer & 1 & $>1$ & S & $\mathrm{Y}$ \\
\hline $\mathrm{T} 4$ & F & China & US & 6 & 0.25 & $\begin{array}{l}\text { Consumer } \\
\text { Operations }\end{array}$ & 5 & $<1$ & $\mathrm{~L}$ & $\mathrm{Y}$ \\
\hline T5 & $M$ & China & US & 6 & 6 & Engineer & 2 & $<1$ & $\mathrm{~L}$ & $\mathrm{Y}$ \\
\hline T6 & M & India & US & 5 & 2 & Engineer & 3 & $>1$ & M & $\mathrm{Y}$ \\
\hline $\mathrm{T} 7$ & $\mathrm{M}$ & China & US & 6.5 & 6.5 & Analyst & 2 & $<1$ & $\mathrm{~S}$ & $\mathrm{Y}$ \\
\hline T8 & M & India & US & 4 & 0.25 & Engineer & 3 & $<1$ & $\mathrm{~L}$ & $\mathrm{Y}$ \\
\hline T9 & M & India & US & 6 & 1.5 & Manager & 6 & $>1$ & $\mathrm{~L}$ & $\mathrm{Y}$ \\
\hline T10 & F & China & US & 1.25 & 1.25 & Engineer & 5 & $>1$ & M & $\mathrm{Y}$ \\
\hline T11 & $\mathrm{F}$ & India & US & 6.5 & 3.5 & Manager & 5 & $>1$ & $\mathrm{~L}$ & $\mathrm{Y}$ \\
\hline T12 & M & India & US & 3.5 & 0.1 & Manager & 5 & $<1$ & $\mathrm{~L}$ & $\mathrm{Y}$ \\
\hline T13 & M & China & US & 4 & 1.25 & UX & $10+$ & $<1$ & $\mathrm{~L}$ & $\mathrm{Y}$ \\
\hline R1 & $\mathrm{F}$ & India & India & 1 & 0 & Planner & 2 & $<1$ & S & $\mathrm{N}$ \\
\hline R2 & $\mathrm{F}$ & India & India & 6.5 & 0 & Optimizer & 2 & $<1$ & S & $\mathrm{N}$ \\
\hline R3 & $M$ & India & India & 1.6 & 0 & Planner & 3 & $<1$ & S & $\mathrm{N}$ \\
\hline R4 & $\mathrm{F}$ & India & India & 1 & 0 & Optimizer & 3 & $<1$ & S & $\mathrm{N}$ \\
\hline R5 & M & India & India & 0.75 & 0 & Planner & 3 & $<1$ & M & $\mathrm{N}$ \\
\hline R6 & M & India & India & 5.5 & 0 & Manager & 4 & $<1$ & $\mathrm{~L}$ & $\mathrm{Y}$ \\
\hline R7 & M & India & India & 1 & 0 & $\begin{array}{l}\text { Consumer } \\
\text { Operations }\end{array}$ & 3 & $<1$ & S & $\mathrm{Y}$ \\
\hline R8 & $\mathrm{F}$ & China & China & 6 & 0.25 & Analyst & 2 & 1 & M & $\mathrm{Y}$ \\
\hline R9 & $\mathrm{F}$ & China & China & 2.5 & 0 & Engineer & 2 & $<1$ & S & $\mathrm{Y}$ \\
\hline
\end{tabular}

working remotely with those in the US and other countries and transnational teams in which Indian and Chinese participants moved to the US to be co-located with their teammates. We label these participants in two groups. Since the terminology of migration is often problematic and inaccurate [26], we use the term "Transplants" for the latter. Borrowed from the language of ecology, this term indicates a move from one environment to another, making it more contextually appropriate. By contrast, "Remotes" refer to participants working from their home country, in these cases, based in Bangalore, Beijing, or Hyderabad.

Some structural differences between these two groups should be noted at the ouset. First, the average number of team members was somewhat different between the two groups. Remotes reported around ten members being involved in their current team, whereas Transplants frequently reported much larger team sizes. However, there was not a discernible difference in the number of team members with whom participants worked directly. Most worked closely with five or fewer colleagues. Second, Transplants reported quite varied tenures with their current teams, ranging from two months to over five years, while Remotes had all worked with their current team for a year or less. This is representative of recent growth in PrimaTech's workforce. The number of offices with which they regularly collaborated was also variable. Transplants typically worked across more than four offices, but all had some co-located colleagues. Remotes, on the other hand, worked across three or fewer offices on average. Moreover, they were often the only member of their team based in their office. So, while Transplants were mostly part of the hub in a hub-and-spoke or hub-to-hub model, 
Remote participants were often spokes in this sort of model [27]. These structural differences further distinguish the two configurations, but we focus primarily on the context of location, as it had a more important impact on social relationships.

\subsection{Analysis}

Although we were interested in comparing Transplants with Remotes, we did not have strong hypotheses about what differences would emerge. Therefore, we used grounded methods [28] in our initial analyses. We used the software Dedoose to aid in data analysis while engaging in an abductive, iterative process of comparing data and relevant research literature and theory. We began with open-coding to discover patterns and recurring themes in our initial round of interviews, then created memos to refine our ideas. This guided data collection as well as our targeted sampling. We then conducted closed coding, applying lower-level codes to categories to identify emergent concepts. We found that much of what emerged related to differences in expectations involving social relationships, and thus we used Nahapiet and Ghoshal's theory of social and intellectual capital in framing our findings [23].

\section{Social Capital and Configuration}

Many points of interest emerged from our interviews, but most salient were interpersonal relationship differences among Transplants and Remotes. In our findings, we discuss the elements of social capital, which Nahapiet and Ghoshal decompose into three dimensions: the structural, the cognitive, and the relational dimensions. These dimensions of social capital in turn impact the conditions for exchange and combination of intellectual capital [23]. It was out of the scope of this research to investigate the structural dimension within PrimaTech. The structural dimension is concerned with network connections between actors, which would require social network analysis. Thus, we focus primarily on the cognitive and relational dimensions. First, we touch on the differences in expectation between participants in the two configurations. Then we highlight the factors that play a role in shaping cognitive and relational social capital, respectively, and discuss how these impact the ability of the team to create new intellectual capital. We also discuss implications of social capital at an individual, team, and organizational level. Finally, we introduce some mechanisms that appear to mitigate these challenges.

\subsection{Configurations and Expectations}

Transplants to the US noted very different experiences with team colleagues than Remotes. The ways in which the two different groups of participants perceived their interpersonal relationships with colleagues were, in part, predicated upon their expectations. In turn, those expectations were based upon their location and the team configuration. Those who had moved to the US generally noted disappointment in their lack of social bonds with teammates. On the other hand, remotes approached these relationships with a pragmatism that showed reserved expectations.

Transplants. Those who moved to the US came for a variety of reasons, personal and professional, but amongst the various expectations, social relationships were a priority. 
But as other narratives of migration [29] have shown, lived experiences often do not meet expectations, especially when it comes to a sense of social belonging. One reason for this is that social relationships at work are often strong in India and China, but are much more compartmentalized in the US [30]. Thus Transplants often experience moving from a situation with close relationships and strong social capital to one in which there seems to be a void. One participant, who had worked first in her home country of India before coming to the US highlights this differentiation: "When I used to work in India, work relationships were much more friendly. The demarcation between work colleagues and friends is a lot fuzzier...Here, it's just that they are not friends- we don't meet up as families and don't socialize." (T11) While this is typically recognized beforehand, as one prepares to move, it still serves as a shock to many Transplants. They move from having quite rich social relationships with coworkers to having much weaker social capital, regardless of their tenure, as we discuss below. Though this difference in work/life compartmentalization is usually known before a Transplant arrives, there is still an expectation of building work-based social relationships. Expectations may be dimmed a bit, but they are still there. The transplants we interviewed did work to cultivate relationships, yet many noted tribulations with creating social relationships, even after years at the same location. The troubles of expatriates integrating into host communities is not a new concept [31]. But it is worthwhile to note that even with the knowledge of work/life difference and even after attempts at trying to create stronger social relations, expectations still led to disappointments.

Transplants desired stronger relationships, but were unsure of how to do it: "It's difficult to get along with the rest of the team as well as I could." (T11) And often, this led to feelings of distress or regret: "I should do more. I go out and have dinner, but sometimes it feels like it's really hard to fit in, no matter how hard I try." (T2) In many instances, this led to feelings beyond a desire for social engagement, into a deeper level of identity. One participant, who had Anglicized his Chinese name, felt as if colleagues did not know who he is: "They only see the way I work. They see 'working [name].' My Chinese name is hard to pronounce... So, they don't know my name. They don't see my social aspect, so they are not comprehending me. Work is just one slice of me." (T13) For those who have just moved, this struggle to create interpersonal relationships is especially salient. But, notably, this lack of social capital does not appear to improve with time spent at the US office. One participant, who has been in the US for over 20 years and working at PrimaTech's US headquarters for over eight (T11), indicated a high level of frustration with this aspect of her work.

Remotes. In contrast, Remote participants indicated that while they realize they cannot fully socialize with distributed colleagues, they felt that they do have close enough relationships. This highlights an adjustment in expectations; distance tempered expectations of social relationships. Employees working on distributed teams at PrimaTech typically meet all colleagues with whom they work closely within the first three to four months of being on a project, so most Remote participants had had the opportunity to meet their colleagues, either through travel to other offices, or through their colleagues visiting the office in India or China. Participants cited that these visits gave them a better sense of their colleagues. Beyond the bonds created through visits, information and communication technologies (ICTs) served as the way through which they maintained social connections. Several participants said they talk informally with distributed colleagues over 
collaborative technologies such as chat or in the first minutes of a video conference: "We do a lot of that- talking about movies, what we've been doing over the weekend. I feel like I know them as colleagues." (R3) These participants generally felt that their distributed colleagues had accurate perceptions of them as colleagues, though nothing approaching deep connections as "friends."

In sum, expectations based on team configuration and location within that configuration played a role in perceptions of social relationship. Transplants expected deeper friendships than they got; Remotes found a shallower but sufficient sense of friendship. Next, we take a look at factors that play a role in whether social capital is developed and how that impacts intellectual capital.

\subsection{Social Capital Factors and Intellectual Capital in Transnational Teams}

When working across cultures, some behaviors will converge, some will diverge. As Hinds et al. note, there must be some degree of convergence for collaboration to work [11]. In our research, a few factors stood out as limiting convergence, particularly for Transplants. We highlight these factors through the framework of social capital, first focusing on the cognitive dimension, then the relational, though both are interrelated to an extent. In delineating these factors, we investigate how they impact conditions necessary for exchange and combination of intellectual capital in the organization.

Cognitive Social Capital. Nahapiet and Ghoshal describe the cognitive dimension of social capital as shared cognition that is facilitated through shared codes and language as well as shared narratives [23]. Shared codes and language are important for the establishment of social relations and thus the ability to exchange information, but beyond that, they also influence perception, meaning the perceived value in sharing information and the ability to combine it meaningfully. Similarly, shared narratives impact interpretability of information.

Small Talk/Topics of Interest. "Small talk," as Goffman explains, is a bracket to larger social affairs that has bearing on the overall relation of participants in an interaction [32]. Thus, it is an important mechanism for establishing stronger capital. Engaging in small talk is a ritualistic interaction that quite easily occurs within groups that have a shared cognitive base. However, engaging in small talk can be quite difficult across cultures due to lack of shared codes and narratives. In our interviews with PrimaTech employees, many Transplants reported difficulties with small talk, noting that they often don't understand the topics at hand. One participant explained: "People go out to lunch every day and have a lot to talk about. It's hard to get it all if it's not work related." (T10) She went on to explain she realizes that her different background influences the perception of what is interesting, so she finds it easier to chat with other Chinese, rather than struggle to find interesting topics to discuss with her American colleagues. For this participant, the lack of common topics was so salient that it influenced her to end lunchtime socializing, further isolating her from her teammates.

In contrast, many Remotes reported not only engaging in small talk in the beginning moments of a video conference, but finding enjoyment in it. So, while Transplants reported finding topics of conversation and small talk difficult, Remotes generally reported small talk as a great way to engage with colleagues for a few 
moments at the beginning or end of a meeting. This difference relates back to expectation issues, particularly with regard to the length of time one must socialize; having a short chat at the beginning of a video conference does not create a burden, whereas sustaining small talk for an hour of lunch may appear daunting. Similarly, Remotes frequently noted that they talked about movies, travel, and weekend plans as topics of conversation, which are fairly general and not highly location-specific, whereas Transplants had higher expectations placed upon them. Transplants noted pressure to know more about local sports or politics, both of which require more of a shared cognitive framework. It may also be the case that Transplants have to engage in this talk with many more people, potentially from many various backgrounds, feeling more pressure yet. One Transplant (T12) noted that so many people ask how his weekend was on Mondays that he plans out what he wants to say in advance, on his way to work. Thus, it appears that whether one only occasionally chats with teammates versus having regular, extended contact with them affects one's perception of whether small talk is a problem or a benefit in building social capital.

Cultural References. Whether part of small talk or part of general work discussions, culturally-specific references can impact one's ability to understand or engage in conversation. This can cause disengagement from social interactions, and, worse, can impact the ability to participate fully in meetings. Cultural references can create misunderstandings of the message itself, but beyond that, they can create confusion about tone. Several Transplants noted that technical conversations were typically fine until cultural references were applied within them, such as a person referring to an idea being "out in left field." This participant elaborates: "I think they tend to use examples from games or football references, so sometimes can't tell if they're being sarcastic or not. It becomes difficult." (T12)

On the other hand, Remotes generally used cultural references as a kicking-off point for understanding their colleagues better. One participant explained: "What is nice and what is fun for us - watching cricket here-is like baseball, basketball there. So watching sports connects people. When someone talks passionately about a match, I understand because I go equally bonkers over cricket." (R2) These Remotes reported that if they do not understand a cultural reference, this allows them to then ask questions to get to know each other better. One possibility for these different attitudes toward the use of cultural references is that there may be an implicit assumption that people will understand most references if they are living in the same location. On the other hand, when talking with someone who lives halfway around the world, individuals may hold fewer assumptions of what others do or do not know about another's culture. Remotes, it seems, are expected to not know everything; Transplants, however, are co-present and expected to know what other locals know.

This may be intensified by the fact that those in the US headquarters typically work with a higher number of distributed offices. So, as one participant points out, you must know about many more cultures: "I didn't socialize so much this past year just because I myself haven't fully plugged in to American culture. And my work and my mind's resources have limited me from doing that. I have to be distributed in many places with all the offices we work with, so I didn't spend much time to figure out local things here." (T13) This highlights that, beyond transnational context, the configuration of the team and the participant within the team really does matter in 
terms of creating social capital. Expectations from others and from oneself are shaped by location, and in turn, location influences the development of social capital. Lack of shared language, codes, or narrative can serve as a kicking-off point for sharing, which enable conditions for exchange, while assuming these are shared closes off the possibility for exchange.

Humor. Humor is an intensely social experience that provokes strong emotions [33]. As such, it can serve as a building block for social capital. But, humor is notoriously difficult to understand across cultures. One Transplant explained: "The most difficult thing here is to make a joke... It connects to many things out of the workplace... But a joke is very important for people's emotional connection. And I cannot connect that way. That is most difficult." (T13) Both Transplants and Remotes reported difficulties with humor, but Remotes had a more generally positive attitude about its impact. Several Remotes explained that joking around became easier for them to handle once they had met their colleagues in person: "Sometimes I don't know how to respond if someone is sarcastic... but everything is easier once you meet- like jokes. Because I've met him and know he's doing it for fun, that barrier gets broken." (R7) Thus, this lack of shared cognition impairs both configurations, but to a different degree. While humor is still difficult for both, it appears that Transplants, being located together, may attempt to understand humor on a deeper level, while Remotes seem satisfied to identify only when humor is being used, as it helps to understand context and tone.

Relational Social Capital. The relational dimension of social capital centers on the interactional and behavioral elements between parties. Nahapiet and Ghoshal describe this dimension in terms of trust, norms, obligations, and identification. They illustrate how these impact intellectual capital by influencing access to parties, perceived value and the motivation to exchange and combine information [23].

Trust. There has been much research on basic trust differences across cultures [34, 35]. Core values play a significant role in base levels of trust as a cognitive factor, but trust is also a dynamic property of relationships in context. Rocco et al., for instance, found a positive relationship between non-work communication and trust [36]. So, trust both shapes and is shaped by interpersonal relationships; when ties with work colleagues are not strong, a strong level of trust is not manifest and vice-versa. Thus, we found trust to be an issue both before and after a relationship has been established.

Despite trust being an oft-cited component of PrimaTech's organizational culture, trust among colleagues was complicated. One Transplant explained the differences in levels of trust with colleagues in the US versus India in the following way: "The meaning of a relationship here is different... In India you don't distinguish between social friends and professional ones. You trust all friends equally. Here it is very professional... I won't trust any friend here as I would in the Indian office." (T12) From this perspective, it appears trust can be gauged a priori. But others mentioned that trust requires rapport, thus it is also impacted a posteriori.

These complexities of trust fundamentally affect group work, whether co-located or distributed. However, trust issues were mentioned more frequently among Transplants than Remotes. One school of thought indicates that this might be due to "swift trust." Jarvenpaa and Leidner found a lack of cultural effects in looking at trust in 
global virtual teams [37], and they suggested these teams can rely upon trust that is based more on categorical expectations than interpersonal relationships, known as swift trust [38]. For Transplants, other factors impact interpersonal relationships, which then impacts trust a posteriori. For Remotes, though, trust is based more on team members' work effort and less on personal factors and is only expected to be sufficient, not deep. This is enhanced by visits in which brief contact allows for a sense of good rapport. While this does not mean that trust from Remotes is necessarily stronger in any sense, it may serve as less of an impediment as compared to co-located teams that may struggle with interpersonal issues.

Speaking Up: Norms of Openness. PrimaTech's organizational culture is often described as being very "bottom-up." Being "bottom-up" means that change is often initiated in a very democratic, communal way. As such, being involved in discussions and decisions means embracing the norms of openness and speaking up. This social norm of openness is noted as a key feature needed in knowledge-intensive firms [39].

"Speaking up" was the most frequently self-cited focus of behavioral change for participants in both groups and a repeated piece of advice they would give to others. One participant, coming from India noted: "It's difficult to get your head around it because if you've never worked in place like [PrimaTech], it's engrained into you to pay attention to social strata or not to speak up." (T11) This general lack of "speaking up" in meetings creates a disparity in being involved. While this happens for both colocated and remote due to different macro-level social conventions, Transplants have the opportunity to speak up more often. But, being in a new location and not having strong social relations in other ways impacts that. One Transplant even noted her move had a negative effect on speaking up, despite it being a norm at PrimaTech: "I have been less outspoken, more quiet since coming to [US office]. Part of that is because I'm transferring to a new location and I don't know people that well, so my confidence level isn't as high. I think more before I speak...” (T4)

For Remotes, speaking up is also an issue, but due to constraints, teams often structure formal conversations differently. For instance, in video conferences, distributed teams focus more on rotating participation and feedback from the various parties, as large video conferences with spontaneous input from simultaneous audio streams can become chaotic. In the same vein, there is an expectation in remote meetings that people may hold back a bit more; one manager noted that he makes a point of specifically asking what others think in making decisions, noting that often that person would have "a brilliant point of view that was missed." (R6) Remotes tended to recognize speaking up as a potential issue in advance and address, while Transplants' co-located teams perceived no barriers to speaking up, and thus didn't address it.

Notably, outside of formal conversations, those who are co-located also have the opportunity to communicate through a variety of informal channels that are beneficial to being involved in decisions, such as side conversations, hall talk, and "meetings over the water cooler" [8]. But when social relationships with colleagues are not strong, Transplants will miss out on such opportunities to hear and to have their opinions heard informally, which leads to less knowledge exchange.

Feedback. Within these transnational teams, lack of communication sometimes led to less access and motivation to exchange and combine knowledge. In particular, many participants noted how they often do not know when they have made mistakes 
because colleagues are hesitant to provide negative feedback. These behaviors are in contrast to the literature, which indicates that Americans are direct, while Chinese and Indians use indirect speech in order to promote harmony [40]. An Indian participant explained how this is impacted through social relationships, not just hierarchy issues: "This is confounded based on how close you are with colleagues. People get more direct negative feedback in India. Here, with a lot mistakes, you don't get direct feedback. I've had to seek it out. But one reason might be that I've only been here going on four months, so I don't have those relationships yet perhaps." (T1)

Additionally, some participants expressed an inability to understand when their colleagues needed help and feedback. Weak social relations with colleagues made it difficult to know when a team member needed help, unless it was directly requested: "If you want to help a coworker, it's not easy...I don't know how much they need help. . . I wish I had the conception to see when help can be appreciated or accepted." (T13) Again in this instance, there is not necessarily an advantage for Remotes, but communication among Remotes and their colleagues was more explicit, so there were fewer issues and less confusion related to implicit communication norms.

Meals. Breaking bread together is a meaningful social bonding activity. Yet this is a difference for those in the US offices in two ways. First, those who had worked in their home country before moving to the US cited that lunch is quite social in India or China, so it was a surprise to see colleagues in the US eating at their desks: "A lot of people eat lunch alone and keep working here. In China, I would always go out of the way to meet other people for lunch. It's a much more social experience there. You never eat at your desk." (T4) This highlights one of the unmet expectations of Transplants, who sought more social engagement with teammates, but did not always find it. Moreover, when these participants did go out to share meals with colleagues, some were disappointed with the food choices as well as the focus on drinking, which discouraged them from joining. One participant explained that team dinners were uncomfortable because he did not eat meat or drink alcohol. Yet, teammates would often choose restaurants for team dinners based on a good wine list. He noted this limited his participation in team dinners: "You want to give them company and build a relationship, build your network, but you're hungry." (T12)

By comparison, dinners are always part of the agenda when Remotes visit their teammates, or when teammates visit them. While less frequent, everyone typically attends, precisely since opportunities to do so are limited, and several Remotes cited good experiences getting to know their distributed counterparts this way.

Families. Finally, getting to know colleagues' families was a significant difference. Most Transplants cited their US-based colleagues' strong work/family divide, noting how different this was from their home culture. This supports the literature on this topic, which references how familial collectivism is more common in Asian cultures and is expressed in business relationships through socializing with families, among other things [11]. Participants based in the offices in India and China often mentioned socializing with colleagues' families. While it is not possible for this to be much of a part of distributed teammate bonding, several Remotes did cite introducing visiting colleagues to their own families, a point of difference based on distance limitations. 


\subsection{Impact on the Individual}

When transnational teams work together, they face many issues that may impede success. As we have seen so far, lack of social capital impacts a team's information exchange and knowledge creation. But importantly, it also impacts the individual dramatically, which in turn can also affect the team.

Career Development. PrimaTech has a promotion process that is heavily influenced by one's peers, which is a unique aspect of the company that all employees encounter. Though most people appreciated the fundamental idea of this process, many participants expressed some level of concern about the importance of relationships. The idea of colleagues, rather than just managers, having a significant impact on career advancement is of much greater concern when one feels he or she does not have strong social capital with colleagues. This was understandably more of a concern for Transplants, who had difficulties building these relationships. One participant remarked: "Making friends is relevant to career growth. It's very difficult to do. You have to talk about children's soccer games and golfing, and I'm not interested... but in order to get people to help and evaluate you, you have to." (T2)

This policy is employed company-wide, so those at international offices review and are reviewed by not only their co-located peers, but their distributed teammates as well. Interestingly, Remotes did not indicate strong concerns with this process, indicating that anxiety about this process is perhaps induced by the local context of Transplants. Remotes may not have developed very strong social capital with colleagues abroad, but expectations for this remain low, and thus they feel their work, not their relationships, is what is being evaluated. Moreover, Remotes straddle different social worlds and arenas and thus have strong social capital in their home location. Even though their US-based colleagues may have more weight in reviews, these local relationships perhaps provide some reassurance in terms of feeling social cohesion, and thus less anxiety about the process. Transplants, in contrast, have major ties with their US-based colleagues, which lead to different expectations and different things expected of them.

General Satisfaction. Ostensibly, participants' enjoyment of their job was also influenced by local contexts. Previous research has shown mixed results in terms of satisfaction in diverse teams [15], but in general supports the claim that distributed, virtual teams have lower satisfaction [41]. Despite this, Remotes seemed more satisfied in certain ways, likely due to better social circumstances. Remotes, who unanimously noted close friendships with colleagues in their home country office, mentioned that they would hang out and socialize more in the office. They were more willing and interested in staying around the office for a while, even though they often worked long hours to accommodate distributed teammates on other continents.

In contrast, Transplants often cited the challenges of their local context. One participant gave this report of dissatisfaction through this solemn advice: "Be prepared that people will misunderstand you. And though you're in [PrimaTech] for five years in India, you have to prove yourself again over here... You don't think of how hard it can be. If you are not used to staying alone or fighting alone, don't join." (T12) 


\section{Mechanisms That May Aid in Convergence}

What emerges from the findings of this study is the importance of focusing on the local in global work. Team configuration and the context of location play important roles in transnational collaboration and have significant implications for teams and individuals, particularly in how a team maintains social cohesion and a sense of community. This in turn impacts the conditions necessary for the exchange of intellectual capital. But, as Hinds et al. note, there must be some degree of convergence for collaboration to work at all [11]. Despite the many points of difference, there are mechanisms that did help teams collaborate. Here, we present ideas as to what might help develop social capital in these transnational collaborations. Emerging from our interviews, we find that an organizational "cultura franca" may help create stronger bonds, and that hiring practices may influence the possibility of convergence. In other words, organizational culture may mitigate some effects of different national cultures.

\subsection{A Cultura Franca}

The idea of a "cultura franca" is an inchoate idea that emerged in this study. It is based on the concept of a lingua franca, or bridge language, used to communicate between parties with different mother tongues. We use the term cultura franca, rather than organizational culture, to indicate that the strong, distinctive culture of PrimaTech serves as a bridge across diverse global cultures and creates a space for common goals and values. Like a lingua franca, it serves as a vehicle for mutual intelligibility-in this case, of practices and priorities, rather than language. Additionally, just as pidgin languages based on a lingua franca evolve in certain locales, the term cultura franca indicates that the culture is not completely uniform across all the geographies; it becomes imbued with attributes of the location.

Throughout PrimaTech, the cultural values of the organization are evident. All participants had very similar ideas about the organizational culture and frequently used the same, or similar, terms to describe it. The most oft-cited descriptors were "open" or "transparent," followed by "democratic," "independent," and "trusting." Many also described the culture in terms of things being "data-driven" and people being "smart" and "friendly." While these were considered to be universal qualities of the organization, there were mixed indications as to how similar the culture is across offices. Because PrimaTech's offices are very similar in physical environment, structure, and character across the globe, many referenced these as indications of uniformity. So, many believed that the culture was quite uniform: "They have done an amazing job of spreading the culture all over the globe...It's pretty much the same." (T9)

But on the other hand, many others indicated that, while the culture is promoted the same way across the globe, the way it is actually exhibited in different offices is not necessarily the same: "From people I've met, the [PrimaTech] culture is the same. Although the way we go about it is completely different." (R7) It appears that, though the values that permeate PrimaTech are fairly universal, the way in which they impact work relationships depends more on the location and local culture therein. The social environment is often adapted to fit better with the local culture. For instance, participant R2 noted that, unlike in the US, alcohol is not involved in office activities in 
India. One participant describes these variations: "The basic things are similar across the geographies, but it's a bit different because of other cultural differences... But in work ethic, it is the same..." (R4) The cultura franca, then, serves as a mechanism to bridge what might otherwise be major differences in values. It seems that the cultura franca of the organization may perhaps ease some factors that negatively impact collaboration, while still enabling diverse perspectives, but to what extent it enables convergence remains a question.

\subsection{Selection in Hiring}

The development of this sort of organizational culture is in part predicated upon the population that is initiated into it. A factor that clearly emerged from our interviews was how the organization selects for those who embody the qualities that PrimaTech promotes. This is a fairly obvious factor in mediating intercultural differenceselecting people who are similar in certain ways-but from our research, the importance of this process was quite distinctive at PrimaTech, enabling the organization to more readily mitigate intercultural challenges. While most participants did not indicate that they considered the organization to be culturally American or Western, one participant explained that the company chooses people who are more culturally aligned to certain values, and that this enables easier collaboration: "At [PrimaTech], it is very different from other Indian companies. I have friends in [other companies], $\ldots$ and they have a lot more issues. I think this is due to [PrimaTech's] interview process. Each person is specifically selected for how they will match..." (R3) While this selection may or may not be explicit_or true on a broader scale-the process of choosing certain qualities is quite explicit, at least internally. One participant explained how there were "unwritten rules" in the hiring process, noting the importance of the social: "Can you sustain a two-hour layover at an airport and not get bored and want to talk to this person?" (R6) He noted that this creates a basis -"the common denominator"-for having somewhat similar employees throughout PrimaTech's global locations. Thus, while not necessarily being specific, there is a template for what is sought out socially in an employee. And since this process is held worldwide, it contributes to cultivating a workforce that reflects the values of the company, irrespective of national culture or other cultural traits.

\section{$5 \quad$ Discussion and Conclusions}

We conducted research within a large multinational technology company to better understand the mechanisms by which people conduct transnational work. While common sense says that presumably co-located work is easier and better for teams, the issues are more complex, especially in intercultural collaborations. From our interviews we found that social capital is, in part, impacted by whether the person is in their home context or transplanted, which in turn impacts the individual, the team, and the organization.

As our results show, location and configuration played a significant role in creating expectations, so it is also important to discuss how these expectations relate to lived experiences. Stronger and richer social capital were expected by Transplants; this led 
to disappointment when those expectations weren't fulfilled. This brings up issues of adaptation. In the literature on migration, it seems that findings generally indicate that the adaptations are made to accommodate the host culture. This was only supported to some extent in our interviews. Transplants adapt at some surface level, but not necessarily at a deeper level: "For myself, I have changed a bit over time. When I came to US, I still had the typical way Chinese do things. But now it is probably more mixed. To do many things, I do things closer to the Western way. But in thinking, I am still pretty Chinese." (T5) While we found only minor evidence of adaptation in terms of social bonding, it remains unclear to what extent participants' colleagues adapted to their behavior, clouding the issue further.

Previous research on immigrants has shown that surface-level adaptations may be made through the use of "relational templates" and that people may maintain multiple templates in engaging in intercultural work. [42] This concept works fairly well in explaining Remotes' interactions with distributed teammates: they maintain their capital with colleagues in their home office and colleagues in distributed offices in systematically different ways. So, you work with your colleagues in Bangalore in one way, but when you call the London office, for instance, you use a different behavioral pattern. While participants did not heavily cite cultural training provided by the organization, it seems that this may be another mediating factor-being able to clearly select and apply appropriate relational templates. Templates seem to be a useful concept in thinking about distributed work. However, with the case of Transplants, it is difficult to see how a template structure would hold, making adaptation more difficult. As indicated in the interviews, the US offices are quite multicultural, unlike offices such as Bangalore or Beijing, which tend to be quite nationally homogenous. When constantly surrounded by a local, heterogeneous team, it is impossible to have a single template that is appropriate for everyone. It is beyond the scope of this study to evaluate the degree of adaptability or co-adaptability of the team; however it seems the field of transnational research would greatly benefit from a more micro-level, longitudinal analysis of changes in behaviors based on the context of location.

Implications. Our results raise interesting questions for the configuration of teams. Are the social costs of moving around the globe more than the coordination costs of working at a distance? This has interesting implications for organizational structure, individual choices, and seemingly, technology.

A team is not merely a division of labor, so it is important to be reflective about organizational structure. Distance issues in teams are well known, but with the highlysystematic methods of interaction in distributed team, one wonders whether Remotes and these teams are reaching their full potential in such configurations. On the other hand, you have situations where workers cross borders to be close to their team. This may ameliorate many of the issues that arise with distance, but it does not mean that conditions for the exchange of intellectual capital will necessarily improve. As we have seen, the interactions that create strong social capital within a team do not necessarily change with proximity. Solid social relationships are the substrate-- the basis on which a team can thrive. When looking at issues of dispersion-temporal, spatial, configurational-it is necessary to also heavily consider how this interacts with cultural differences. 
Beyond this, though, it seems more emphasis could be placed on organizational culture and human resources practices. On a practical level for the individual, it could be that, despite all its challenges, distributed collaboration provides a more optimal, structured format for intercultural work in that it requires less adaptation and concern for divergent cultural challenges. The limited contact inherent in distributed collaboration means that workers in their home country may experience more satisfying social interactions than those who move across borders to other offices. Put another way: consider, for a moment, PrimaTech's headquarters to be Rome, and how it might be easier to act like a Roman for short chunks of time than to try to become a Roman. But is this better for the team and the organization? If diversity is important, we want to embrace diverse perspectives. Maybe everyone should not have to act like a Roman. Or, maybe Romans should be expected to act differently. These factors would best be addressed through organizational culture and human resources training.

Finally, what are implications here for ICTs? It seems that, for Remotes, technology provided a solution that went "beyond being there" [43] in certain ways. The use of ICTs helped mitigate issues and supported the development of sufficient social capital. In this sense, perhaps what is needed is a return to Hollan and Stornetta's focus on creating technologies that meet needs that cannot so easily be met "in the medium of physical proximity." The realm of social capital is comprised of structural, cognitive, and relational dimensions. Ostensibly, ICTs can aid in structural social capital through the development of networks that connect people, but it seems they can aid in less obvious ways. From this work it is clear that ICTs can also play a role in cognitive and relational aspects of social capital. Moving forward, research in this area would benefit by considering the ways in which technologies can and cannot support development of social capital-distributed or co-located. In being sensitive to these possibilities and limitations, designers, individuals, teams, and organizations can seek more creative ways to build and nurture social bonds in transnational work.

Limitations and Future Work. Several limitations of this work should be noted. This study focused on Indian and Chinese participants in transnational teams; we did not include other nationalities nor the teammates with whom these participants work. Also, while we did visit the US headquarters, we did not visit international sites, and all interviews were conducted via video conferencing. Thus, our findings may be limited by interviewees not talking as openly as they might in person. By relying on interviews alone, we may also be assessing perceived, rather than actual, social capital. Including other teammates (non-transplant, non-remote) and conducting fieldwork that goes beyond a case study of single firm would certainly aid in further investigating these social capital phenomena. This could be a useful starting point for development of a survey instrument that can operationalize and validate some of these constructs, particularly in teasing apart perceived social capital and actual social capital. Future research should focus on creating a better framework for looking at behavioral dynamics in transnational teams, taking the context of location into account. This line of research should also look at whether these effects hold when the dominant culture is non-Western. On a broader level, such research could have broad implications for individuals, team structuring, and organizational mechanisms for co-adaptability. 
Acknowledgements. We thank all the participants in this study for their time and contributions. We thank Google for generously supporting this research.

\section{References}

1. Ryan, A.M., Tippins, N.: Designing and Implementing Global Staffing Systems. WileyBlackwell (2009)

2. Bradner, E., Mark, G.: Why Distance Matters: Effects on Cooperation, Persuasion and Deception. In: Proc. of the ACM Conference on CSCW, pp. 226-235 (2002)

3. Grinter, R.E., Herbsleb, J.D., Perry, D.E.: The Geography of Coordination: Dealing with Distance in R\&D Work. In: Proc. GROUP Conference of the ACM, pp. 306-315 (1999)

4. Koehne, B., Shih, P.C., Olson, J.S.: Remote and Alone: Coping With Being the Remote Member on the Team. In: Proc. of the ACM Conference on CSCW, pp. 1257-1266 (2012)

5. Olson, G.M., Olson, J.S.: Distance matters. Human-Computer Interaction 15(2), 139-178 (2000)

6. Tang, J.C., Zhao, C., Cao, X., Inkpen, K.: Your Time Zone or Mine? A study of Globally Time Zone-Shifted Collaboration. In: Proc. ACM Conference on CSCW, pp. 235-244 (2011)

7. Gelfand, M.J., Erez, M., Aycan, Z.: Cross-Cultural Organizational Behavior. Annual Review of Psychology 58, 479-514 (2007)

8. Hall, E.T.: Beyond Culture. Anchor Books (1977)

9. Hofstede, G.H.: Culture's consequences: International Differences in Work-Related Values. Sage (1980)

10. Gibson, C., McDaniel, D.: Moving beyond conventional wisdom; Advancements in CrossCultural Theories of Leadership, Conflict, and Teams. Perspectives on Psychological Science 5, 450-462 (2012)

11. Hinds, P., Liu, L., Lyon, J.: Putting the Global in Global Work: An Intercultural Lens on the Practice of Cross-National Collaboration. The Academy of Management Annals 5(1), 135-188 (2011)

12. Kraidy, M.M., Murphy, P.D.: Shifting Geertz: Toward a Theory of Translocalism in Global Communication Studies. Communication Theory 18, 335-355 (2008)

13. Zimmerman, A.: Interpersonal relationships in transnational, virtual teams-towards a configurational perspective. Int. J. of Management Reviews 12(1), 59-78 (2011)

14. Page, S.E.: The Difference: How the Power of Diversity Creates Better Groups, Firms, Schools, and Societies. Princeton University Press (2007)

15. Stahl, G.K., Maznevski, M.L., Voigt, A., Jonsen, K.: Unraveling the effects of cultural diversity in teams: A meta-analysis of research on multicultural work groups. J. of International Business Studies 41, 690-709 (2010)

16. Gibson, C.B., Grubb, A.R.: Turning the tide in multinational teams. In: Shapiro, D.L., Von Glinow, M.A., Cheng, J.L. (eds.) Managing Multinational Teams: Global Perspectives, pp. 69-96. Elsevier, Oxford (2005)

17. Castells, M.: The Rise of the Network Society (1996)

18. O'Leary, M.B., Mortensen, M.: Go (Con)figure: Subgroups, Imbalance, and Isolates in Geographically Dispersed Teams. Organizational Science 21(1), 115-131 (2010)

19. Gorton, I., Motwani, S.: Issues in Co-operative Software Engineering Using Globally Distributed Teams. Information and Software Technology 38, 647-655 (1996)

20. Gupta, A., Mattarelli, E., Seshasai, S., Broschak, J.: Use of Collaborative Technologies and Knowledge Sharing in Co-located and Distributed Teams: Towards the 24-h Knowledge Factory. J. of Strategic Information Systems 18, 147-161 (2009) 
21. Ramasubbu, N., Mithas, S., Kemerer, C.F.: Work Dispersion, Process-Based Learning, and Offshore Software Development Performance. MIS Quarterly 32, 437-458 (2008)

22. Olson, J., Olson, M.: Culture Surprises. Queue, 52-59 (December- January 2003)

23. Nahapiet, J., Ghoshal, S.: Social Capital, Intellectual Capital, and the Organizational Advantage. The Academy of Management Review 23(2), 242-266 (1998)

24. Irani, L., Vertesi, J., Dourish, P., Philip, K., Grinter, R.E.: Postcolonial computing: A lens on Design and Development. In: Proc. of the ACM Conference on Human Factors in Computing Systems, pp. 1311-1320 (2010)

25. Deming, W.E.: Sample Design in Business Research. John Wiley \& Sons (1990)

26. Burrell, J., Anderson, K.: 'I have great desire to look beyond my world': trajectories of information and communication technology use among Ghanaians living abroad. New Media and Society 10, 203-224 (2008)

27. Olson, G.M., Olson, J.S., Venolia, G.: What Still matters about distance. In: Proc. of HCIC (2009)

28. Glaser, B.G., Strauss, A.L.: The Discovery of Grounded Theory: Strategies for Qualitative Research. Aldine de Gruyter (1967)

29. Narayan, S.: Return to India: One Family's Journey to America and Back. Special Report. Wharton, http: / / knowledge. wharton. upenn. edu/india

30. Morris, M.W., Podolny, J., Sullivan, B.N.: Culture and Coworker relations: Interpersonal Patterns in American, Chinese, German, and Spanish Divisions of a Global Retail Bank. Organization Science 19, 517-532 (2008)

31. Breton, R.: Institutional Completeness of Ethnic Communities and the Personal Relations of Immigrants. American Journal of Sociology 70(2), 193-205 (1964)

32. Goffman, E.: Forms of Talk. University of Pennsylvania Press (1981)

33. Weisfeld, G.E.: The Adaptive Value of Humor and Laughter. Ethnology \& Sociobiology 14(2), 141-169 (1993)

34. Cai, D.A., Hung, C.J.: How relevant is trust anyway? A cross-cultural comparison of trust in organizational and peer relationships. In: Cheney, G., Barnett, G.A. (eds.) International and Multicultural Organizational Communication, Hapton, pp. 73-104 (2005)

35. Yuki, M., Maddux, W., Brewer, M., Takemura, K.: Cross-Cultural Differences in Relationship- \& Group-Based Trust. Personality and Soc. Psych. Bulletin 31, 48-60 (2005)

36. Rocco, E., Finholt, T.A., Hofer, E.C., Herbsleb, J.D.: Designing as if trust mattered. CREW Technical Report, University of Michigan (2001)

37. Jarvenpaa, S.L., Leidner, D.E.: Communication and trust in global virtual teams. Organization Science 10(6), 791-815 (1999)

38. Meyerson, D., Weick, K.E., Kramer, R.M.: Swift Trust and Temporary Groups. In: Kramer, R.M., Tyler, T.R. (eds.) Trust in Organizations: Frontiers of Theory and Research, pp. 166-195. Sage, Thousand Oaks (1996)

39. Starbuck, W.H.: Learning by knowledge intensive firms. J. of Management Studies 30, 713-740 (1992)

40. Ulijn, J., Li, X.: Is Interrupting Impolite? Some Temporal Aspects of Turn Taking in Chinese-Western \& Other Intercultural Business Encounters. Text 15(4), 589-627 (1995)

41. Geister, S., Konradt, U.: Effects of Process Feedback on Motivation, Satisfaction, and Performance in Virtual Teams. Small Group Research 37(5), 459-489 (2006)

42. Lubbers, M.J., Molina, J.L., Lerner, J., Brandes, U., Avila, J., McCarty, C.: Longitudinal Analysis of Personal Networks: The Case of Argentinean Migrants in Spain. Social Networks 32, 91-104 (2010)

43. Hollan, J., Stornetta, S.: Beyond Being There. In: Proc. of the ACM Conference on Human Factors in Computing Systems, pp. 119-125 (1992) 